\title{
Hepatectomy for Liver Metastases of Colorectal Cancer After Adoptive Chemoimmunotherapy Using Activated $\alpha \beta$ T-cells
}

\author{
FUMINORI ISHII $^{1}$, YOICHIRO YOSHIDA ${ }^{1}$, YASUSHI YAMAUCHI ${ }^{1}$, NAOYA AISU $^{1}$, \\ DAIBO KOJIMA $^{1}$, TOSHIYUKI MERA ${ }^{1}$, DAISUKE KATO ${ }^{1}$, TOSHIHIRO TANAKA ${ }^{2}$, \\ KEIKO NAITO $^{3}$, KOSEI YASUMOTO ${ }^{3}$, TAKASHI KAMIGAKI ${ }^{3}$, SHIGENORI GOTO ${ }^{3}$, \\ YOSHIHIRO HAMADA ${ }^{4}$, SATOSHI NIMURA ${ }^{4}$, SHOHTA KODAMA ${ }^{5}$ and SUGURU HASEGAWA ${ }^{1}$ \\ ${ }^{1}$ Department of Gastroenterological Surgery, ${ }^{2}$ Division of Oncology, Hematology and Infectious Diseases, \\ Department of Internal Medicine, ${ }^{4}$ Department of Pathology and \\ ${ }^{5}$ Department of Regenerative Medicine and Transplantation, \\ Fukuoka University Faculty of Medicine, Fukuoka, Japan; \\ ${ }^{3}$ Seta Clinic Group, Tokyo, Japan
}

\begin{abstract}
Background/Aim: Various types of chemoimmunotherapies for malignant tumors have been reported. However, there are few reports on hepatectomy after chemoimmunotherapy. We evaluated the safety and efficacy of hepatectomy for patients with stage IV colorectal liver metastases (CLM) after chemoimmunotherapy using activated $\alpha \beta$ T-cells. Patients and Methods: From June 2012 to December 2016, five patients who underwent hepatectomy after receiving capecitabine and oxaliplatin (XELOX) plus bevacizumab and ex vivo-expanded $\alpha \beta$ T-lymphocytes as firstline chemoimmunotherapy were included. Results: The median age of the five patients (two men, three women) was 61.4 (range $=56-75$ ) years. The surgical procedure was partial hepatectomy in two, laparoscopic partial hepatectomy in two, and one case of partial hepatectomy with subsegmentectomy. There was no postoperative complication of Clavien-Dindo grade $3 A$ or higher. One patient had multiple lung metastases. Conclusion: Hepatectomy after chemoimmunotherapy using activated $\alpha \beta$ T-cells for CLM can be performed safely.
\end{abstract}

Recently, immunotherapy has been recognized as an anticancer treatment modality in addition to surgery, chemotherapy, and radiotherapy (1-3). Various types of immunotherapies such as $\alpha \beta$ T-cell, $\gamma \delta$ T-cell, natural killer (NK) cell, and dendritic cell (DC) vaccine therapies

Correspondence to: Yoichiro Yoshida, Department of Gastroenterological Surgery, Fukuoka University School of Medicine, 7-45-1 Nanakuma, Jonan-ku, Fukuoka 814-0180, Japan. Tel: +81 928011011, Fax: +81 928639759, e-mail: yy4160@yahoo.co.jp

Key Words: Colorectal cancer, chemotherapy, immunotherapy, XELOX, hepatectomy. for malignant tumors have been reported (4). Furthermore, immune checkpoint blockade therapy has further increased the focus on immunity in cancer treatment (5). Therefore, we conducted a clinical trial called COMVI study to evaluate immunotherapy with chemotherapy as a first-line therapy aiming at improvement of the effect for advanced colorectal cancer (CRC) (6). We treated patients with capecitabine and oxaliplatin (XELOX) plus bevacizumab and ex vivo-expanded $\alpha \beta$ T-lymphocytes in the COMVI study.

$\alpha \beta$ T-Cell therapy is an application of adoptive immunotherapy, which started as activated self-lymphocyte therapy in the late 1980s (7). This method is called CD3activated T-cell therapy. Several studies have reported on the utility of activated self-lymphocyte therapy in ovarian cancer, lung cancer, and hepatocellular carcinoma $(4,8,9)$. The data from these studies suggest that chemoimmunotherapy for liver metastases from CRC (CLM) would be effective and safe. We reported that the combination of adoptive $\alpha \beta$ T-cell immunotherapy and chemotherapy is safe and efficient (1). However, because there are no reports on hepatectomy after chemoimmunotherapy for CLM, as far as we are aware, we aimed to evaluate the safety and efficacy of hepatectomy for patients with stage IV colorectal cancer after chemoimmunotherapy using activated $\alpha \beta$ T-cells.

\section{Patients and Methods}

Patients. The medical records of patients diagnosed with CLM between June 2012 and December 2016 were retrospectively reviewed. Patients with imaging findings and histologically proven CLM with no prior chemotherapy or hepatectomy were enrolled in the study. Furthermore, we included patients with synchronous and metachronous CLM. All patients provided their written informed consent prior to chemoimmunotherapy. 
Eligibility criteria. Patients $>20$ years of age, with histologically confirmed CRC without prior chemotherapy for metastatic disease were included in the study.All eligible patients met the following criteria: Eastern Cooperative Oncology Group performance status (ECOG PS) $0-1$, life expectancy $>12$ weeks, white blood cell count $>3000 / \mathrm{mm}^{3}$, neutrophil count $>1500 / \mathrm{mm}^{3}$, platelet count $>75,000 / \mathrm{mm}^{3}$, hemoglobin $>8.5 \mathrm{~g} / \mathrm{dl}$, total bilirubin $<2.0$ times the upper limit of normal, asparate aminotransferase $<3.0$ times the upper limit of normal, and serum creatinine level $<2.0 \mathrm{mg} / \mathrm{dl}$. Patients with any of following conditions were excluded: interstitial lung disease, autoimmune disease, clinically significant cardiovascular disease, active infection, a history of serious hypersensitivity to drugs, systemic steroid administration, pregnancy, multiple primary cancers within the previous 5 years, microbiologically positive for human immunodeficiency virus or human T-cell lymphotropic virus type 1, or any other condition making a patient unsuitable for this study.

Treatment. Patients received XELOX plus bevacizumab therapy (7.5 $\mathrm{mg} / \mathrm{kg}$ of bevacizumab and $130 \mathrm{mg} / \mathrm{m}^{2}$ of oxaliplatin on day 1 plus $1,000 \mathrm{mg} / \mathrm{m}^{2}$ of capecitabine twice daily on days $1-14$, every 3 weeks) for advanced or recurrent CRC (Figure 1) (10-12). Dose reductions were required for all grade 3 or 4 toxicities attributed to the study medications. The dose of bevacizumab was not reduced. The treatment was continued until there was disease progression, unacceptable toxicity, or withdrawal of consent. Study treatment was delayed if any of the following criteria were applicable on the day of scheduled administration or the previous day: neutrophil count $<1,000 / \mathrm{mm}^{3}$, platelet count $<75,000 / \mathrm{mm}^{3}$, active infection with fever $\geq 38.0^{\circ} \mathrm{C}$, grade 2 or worse peripheral sensory neuropathy (PSN), and other grade 2 or worse non-hematological toxicity. The oxaliplatin dose was reduced to $100 \mathrm{mg} / \mathrm{m}^{2}$ if grade 3 or 4 neutropenia or thrombocytopenia, persistent grade 2 or reversible grade 3 PSN, or any grade 3 or 4 non-hematological toxicity occurred. The study was terminated if grade 3 toxicity persisted after a 21-day washout period or if grade 4 PSN or a grade 2-4 allergic reaction occurred. Furthermore, it was terminated if the patient required longer than 4 weeks to recover from an adverse event.

Peripheral blood mononuclear cells were harvested by centrifugation, and over $1 \times 10^{6}$ harvested cells were cultured with an immobilized antibody to CD3, and interleukin (IL)-2 for 14 days. Over $5 \times 10^{9}$ lymphocytes were obtained on average. The cultured lymphocytes comprised $61 \pm 15 \% \quad \mathrm{CD}^{+}, \quad 30 \pm 15 \% \quad \mathrm{CD}^{+}$ $\left(\mathrm{CD}^{+}: \mathrm{CD} 8^{+}\right.$ratio $=0.8$, on average $)$, and a small percentage of $\mathrm{NK}$ cells and NK T-cells. This indicated that CD8 ${ }^{+}$T-lymphocytes proliferated more intensively than $\mathrm{CD} 4+\mathrm{T}$-lymphocytes during the 2-week culture period (13). Over $5 \times 10^{9} \alpha \beta$ T-lymphocytes cultured ex vivo were injected intravenously into patients on day 17 or 18 once every 3 weeks.

Evaluation of toxicities and effect of chemoimmunotherapy. All patients underwent physical examination, chest radiography and computed tomographic (CT) scans of the abdomen, pelvis and chest before treatment. All patients were included in the safety and efficacy analyses. The severity of adverse effects was evaluated according to the National Cancer Institute Common Terminology Criteria, version 4.0 (14). Tumors were measured at 4-6-week intervals by $\mathrm{CT}$ imaging, and the response was evaluated according to the response evaluation criteria for solid tumors (RECIST), version 1.1 (15). The evaluation of response was based on
Table I. Baseline patient characteristics.

\begin{tabular}{lc}
\hline Characteristic & Value \\
\hline Median age (range), years & $61.4(56-75)$ \\
Gender, $\mathrm{n}$ & 2 \\
$\quad$ Male & 3 \\
$\quad$ Female & \\
Primary tumor location, $\mathrm{n}$ & 1 \\
$\quad$ Ascending colon & 1 \\
Transverse colon & 1 \\
$\quad$ Sigmoid colon & 2 \\
$\quad$ Rectum & \\
Liver metastasis (chronology) & 4 \\
$\quad$ Synchronous & 1 \\
$\quad$ Metachronous & \\
Number of liver metastases & 4 \\
Solitary & 1 \\
$\quad$ Multiple & $117.5(4.5-288.9)$ \\
Median size of largest metastases (range), mm & $118.4(2-490)$ \\
Median CEA (range), ng/ml & \\
Median CA19-9 (range), U/ml &
\end{tabular}

CEA: Carcinembryonic antigen; CA19-9: cancer antigen 19-9.

radiologist-reported measurements. Complete response (CR) and partial response (PR) required subsequent confirmation of response after an interval of at least 4 weeks.

Surgery and follow-up. Patients were considered suitable for hepatectomy after four cycles of chemoimmunotherapy when they showed no extrahepatic disease on imaging findings and had adequate liver reserve function, Child-Pugh A or early Child-Pugh B. The period from chemoimmunotherapy to surgery was approximately 6 weeks. Patients with a preoperative indocyanine green retention rate of $20 \%$ or above at $15 \mathrm{~min}$ were considered poor candidates for major hepatectomy. The patient selection criteria for laparoscopic hepatectomy were toleration of general anesthesia, Child-Pugh A liver function, laparoscopically resectable tumor, and tumor size $<5 \mathrm{~cm}$. Open and laparoscopic hepatectomies were performed by the same surgeons. Intraoperative ultrasound examination was performed to reconfirm the location and check for additional lesions in the rest of the liver. A cavitron ultrasonic surgical aspirator was used for liver parenchymal resection with a margin of at least $1 \mathrm{~cm}$. Postoperative morbidities were classified according to the Clavien-Dindo classification (16).

Immunohistochemistry. All immunohistochemical analyses were performed at Kyodo Byori Inc. (Kobe, Japan) (17). Formalin-fixed, paraffin-embedded blocks were cut into 5 - $\mu \mathrm{m}$ sections and mounted on glass slides. The slides were deparaffinized and incubated for 15 min with hydrogen peroxide and with Blocking I (\#03953-95, Nakaraitesuku, Kyoto, Japan) for $10 \mathrm{~min}$ at $20-25^{\circ} \mathrm{C}$. Immunohistochemistry was performed using mouse monoclonal antibodies against human CD3 (NCL-CD3; Novocastra Laboratories, Newcastle, UK), CD4 (NCL-CD4; Novocastra), CD8 (NCL-CD8; Novocastra), CD56 (NCL-L-CD56; Novocastra), and forkhead box P3 (FOXP3) (eBioscience, San Diego, CA, USA). 


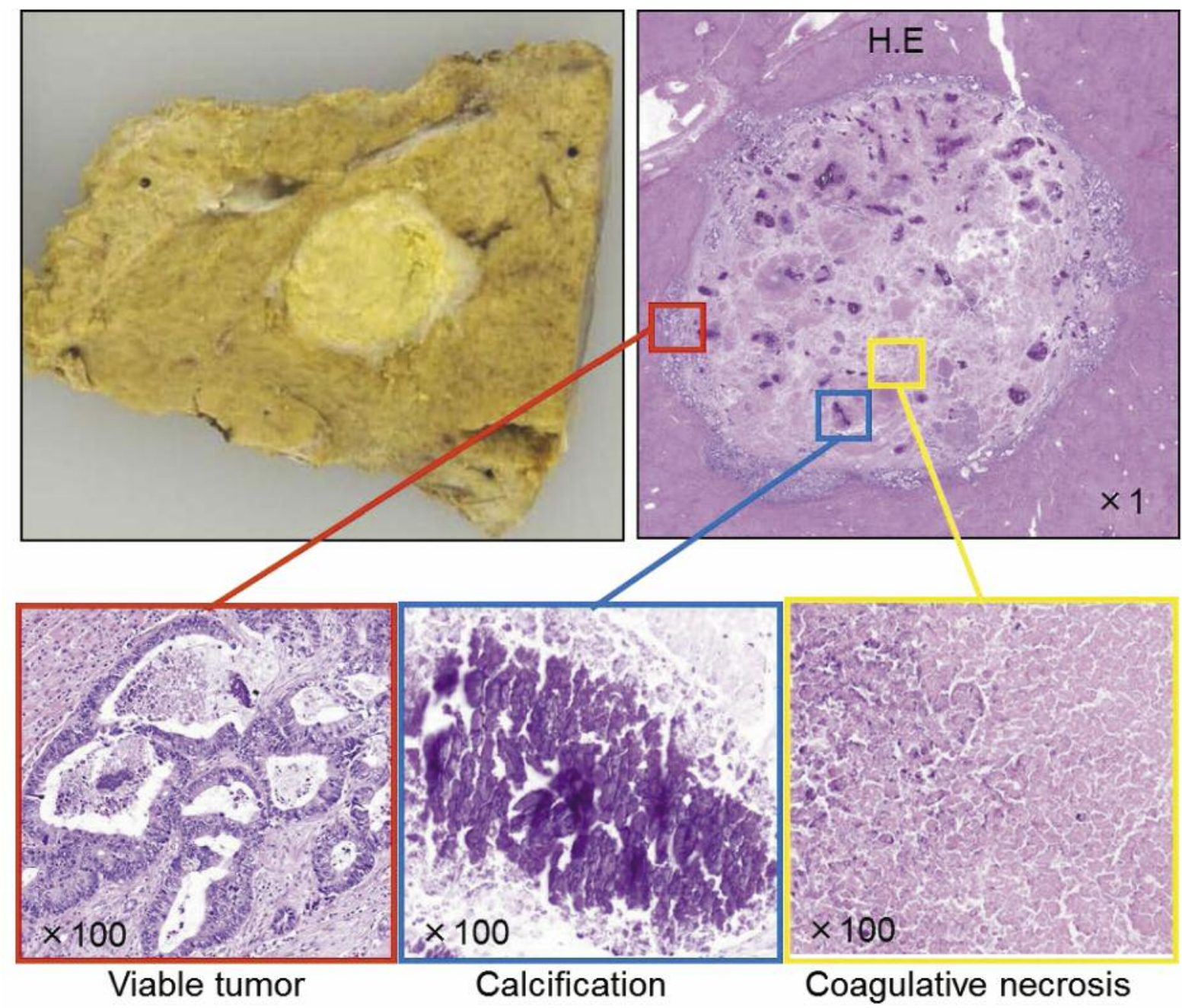

Figure 1. Pathological features of the resected liver. The well-demarcated yellowish-white nodule was composed of differentiated tubular adenocarcinoma with massive necrosis and calcification. Viable carcinoma tissue was localized in the margins of the metastatic nodule.

\section{Results}

Baseline patient characteristics. Patient characteristics are presented in Table I. The median age of the patients (two men, three women) was 61.4 (range $=56-75$ ) years. The ECOG PS was 0 in all patients. Elevation of carcinoembryonic antigen was observed in all four patients with synchronous liver metastases. One patient started chemoimmunotherapy after primary tumor resection.

Treatment. In the administration of XELOX plus bevacizumab with adoptive chemoimmunotherapy using activated $\alpha \beta$ T-cells, the median number of treatment cycles was 10 (range=6-13). Four patients $(80 \%)$ continued treatment through eight cycles and the remaining patient received six cycles.
Efficacy. The confirmed response rate was $100 \%[\mathrm{CR}=20.0 \%$ $(n=1) ; \quad P R=80.0 \% \quad(n=4) ; \quad$ stable disease $=0 \% \quad(n=0)$; progressive disease $=0 \%$ ] (Table II); the achieved disease control rate was $100 \%$. One patient had recurrence of multiple lung metastases. No other patients have yet experienced recurrence. Disease-free survival and overall survival are presented in Table II. Four patients were censored.

Safety. Adverse events for five patients are summarized in Table III. Grade 3 or higher hemotoxicity and grade 3 or higher non-hematological toxicity were not noted. There were no other severe treatment-related adverse events and no deaths during the treatment. There was no prominent hepatic disorder in the preoperative liver reserve test (Table IV). 
Table II. Efficacy of chemoimmunotherapy.

\begin{tabular}{|c|c|c|c|c|c|c|c|}
\hline Case & $\begin{array}{l}\text { Chemoimmunotherapy } \\
\text { (cycles) }\end{array}$ & $\begin{array}{l}\text { Response by } \\
\text { RECIST }\end{array}$ & $\begin{array}{c}\text { CEA }(\mathrm{ng} / \mathrm{ml}) \\
\text { before treatment }\end{array}$ & $\begin{array}{l}\text { Preoperative } \\
\text { CEA }(\mathrm{ng} / \mathrm{ml})\end{array}$ & $\begin{array}{c}\text { DFS, } \\
\text { (months) }\end{array}$ & $\begin{array}{c}\text { OS, } \\
\text { (months) }\end{array}$ & Outcome \\
\hline 1 & 10 & PR & 4.5 & 2.2 & $32 *$ & $32 *$ & Disease-free \\
\hline 2 & 13 & $\mathrm{CR}$ & 211.2 & 4.5 & $25^{*}$ & $25^{*}$ & Disease-free \\
\hline 3 & 8 & PR & 288.9 & 24 & 4 & 17 & Lung metastases \\
\hline 4 & 10 & PR & 65.2 & 1 & $12 *$ & $12 *$ & Disease-free \\
\hline 5 & 6 & PR & 17.9 & 5.6 & $7 *$ & $7 *$ & Disease-free \\
\hline
\end{tabular}

CR: Complete response, CEA: carcinoembryonic antigen, DFS: disease-free survival, PR: partial response, RECIST: response evaluation criteria in solid tumours, OS: overall survival, *censored.

Surgery. Of the five patients, three underwent simultaneous resection of CRC and CLM. Two patients underwent laparoscopic hepatectomy and three patients underwent an open hepatectomy. Partial hepatectomy and subsegmentectomy were performed in one patient for multiple liver metastases (Table IV). There was no postoperative complication of Clavien-Dindo grade 3A or higher. Paralytic bowel obstruction was conservatively improved in one patient who underwent concurrent hepatectomy with ileocecal resection.

Pathological findings. We evaluated the effect of chemoimmunotherapy pathologically. Figure 1 shows that chemoimmunotherapy was effective in one case, in which coagulative necrosis with calcification was observed. All the other cases showed the grade 2 or more effect of treatment. The expression of CD3, CD4, CD8, CD56, and FOXP3 were assessed in the patients who had received chemoimmunotherapy. We show the same patient effectively treated with chemoimmunotherapy (Figure 2). The presence of tumor cells could not be confirmed in one patient. Therefore, their case was judged to be CR. Except for the one case of CR, in the four cases that were available for immunostaining, viable tumor cells remained near the margin of the tumor. A large number of lymphocytes were present in the tumor stroma at the boundary with liver tissue. Most were $\mathrm{CD}^{+} \mathrm{T}$-cells, and there were more $\mathrm{CD}^{+}{ }^{+} \mathrm{T}$-cells than $\mathrm{CD}^{+}{ }^{+} \mathrm{T}$-cells (Table V).

\section{Discussion}

Various methods of immunotherapy have been reported, such as $\alpha \beta \mathrm{T}$ cell, $\gamma \delta \mathrm{T}$ cell, NK cell, or DC vaccine therapy. We treated our patients with chemotherapy and $\alpha \beta$ T-cells because we expected better outcomes through the interaction. Antibody to vascular endothelial growth factor has been reported to enhance the antitumor activity of adoptively transferred antitumor T-cells by the augmentation of lymphocyte infiltration into tumor (18). 5- Fluorouracil appears to upregulate tumor antigen expression on colorectal and breast cancer cells (19); and oxaliplatin induces immunogenic death
Table III. Adverse events during chemoimmunotherapy by CommonTerminology Criteria for Adverse Events ver 4.0.

\begin{tabular}{lcc}
\hline & \multicolumn{2}{c}{ Adverse event } \\
\cline { 2 - 3 } & Hematological, $\mathrm{n}$ & Non-hematological, $\mathrm{n}$ \\
\hline Grade 3 or 4 & 0 & 0 \\
Grade 2 & $\begin{array}{c}\text { Neutropenia: } 1 \\
\text { Thrombocytopenia: } 1\end{array}$ & Hand-foot syndrome: 1 \\
Grade 1 & Neutropenia: 1 & $\begin{array}{c}\text { Diarrhea: } 1 \\
\text { Nausea: } 2\end{array}$ \\
& & $\begin{array}{c}\text { Hand-foot syndrome: } 1 \\
\text { Neuropathy 3 } \\
\end{array}$ \\
& Hypersensitivity: 3 \\
\hline
\end{tabular}

of CRC cells by stimulating pre-apoptotic calreticulin and triggering high-mobility group box 1 protein, with this effect determining its therapeutic efficacy in patients with CRC (20). Chemotherapeutics can induce several beneficial effects on the immune system (21). We previously described the safety and efficacy of chemoimmunotherapy (1). However, to our knowledge there is no report on hepatectomy after chemoimmunotherapy for CLM. Therefore, in the present study we evaluated hepatectomy for patients with stage IV CLM after chemoimmunotherapy using $\alpha \beta$ T-cells. Compared with chemotheraphy alone, chemoimmunotherapy did not seem to affect the preoperative residual liver function or postoperative complications after hepatectomy. We were able to perform hepatectomy safely without any postoperative complications even after chemoimmunotherapy. Although the number of patients was small, chemoimmunotherapy may be more effective than chemotherapy alone. One out of five patients showed CR by RECIST on CT findings and the others showed PR. Because pathological evaluation was necessary for the patient with $\mathrm{CR}$, hepatectomy was performed. No tumor was macroscopically confirmed. One patient had a 

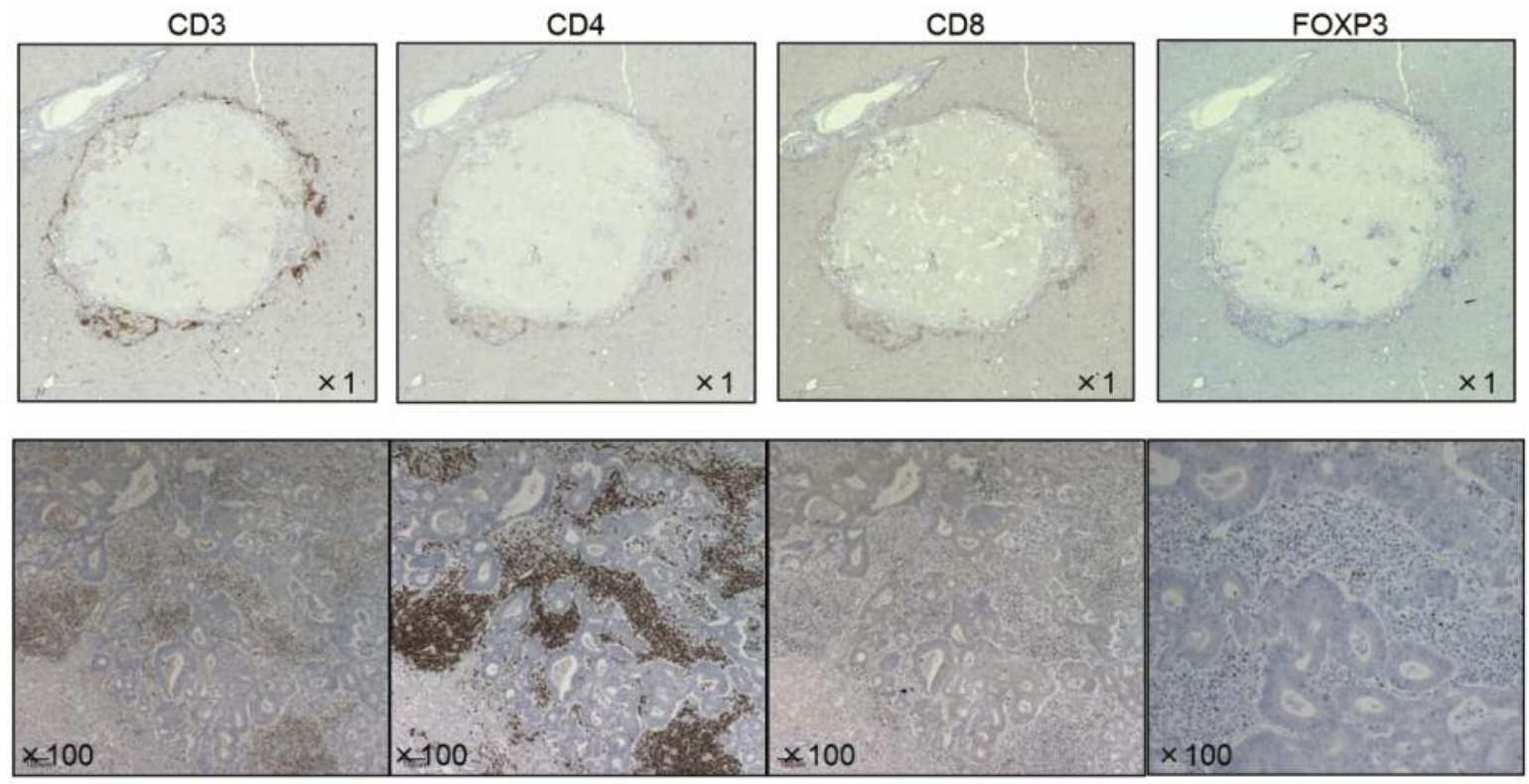

Figure 2. Immunohistochemistry (same specimen as in Figure 1). Lymphocytic infiltration can also be seen in the viable carcinoma tissue. Most infiltrating cells were CD3-positive T-cells, and there were more CD4-positive T-cells than CD8-positive T-cells. The CD4/CD8 ratio was approximately 8:2 assessing 1000 lymphocytes at each site. FOXP3: Forkhead box P3.

Table IV. Liver reserve test and surgical procedure.

\begin{tabular}{ccccccc}
\hline $\begin{array}{c}\text { Case Child-Pugh } \\
\text { class }\end{array}$ & $\begin{array}{c}\text { Indocyanine } \\
\text { clearance (\%) }\end{array}$ & $\begin{array}{c}\text { Hyaluronic } \\
\text { acid (ng/ml) }\end{array}$ & Surgery & $\begin{array}{c}\text { Duration Bleeding } \\
\text { (min) }\end{array}$ & $\begin{array}{c}\text { Complication } \\
\text { (ml) }\end{array}$ & \\
\hline (Clavien-Dindo)
\end{tabular}

prominent calcification, which was thought to be a type of morphological change. There are many reports that the calcification of CLMs is often observed with chemotherapy (22). However, whether it contributes to prognosis extension remains unclear.

To confirm the effect of immunotherapy, we attempted to evaluate the same by immunostaining. We consider that it is important to evaluate the immune response in the liver tissue rather than in the peripheral blood. We measured T-cells of the lymphoid tissues of tumor margins to make the points of measurement of the resected specimens as consistent as possible. Contrary to our expectation, $\mathrm{CD} 4^{+} \mathrm{T}$-cells were more predominant than $\mathrm{CD}^{+} \mathrm{T}$-cells, particularly the lymphocytes surrounding the tumor. In addition, $\mathrm{CD}^{+} 6^{+} \mathrm{T}-$ cells were hardly observed, and $\mathrm{FOXP}^{+}$regulatory $\mathrm{T}$-cells
Table V. Evaluation of Immunohistochemical staining.

\begin{tabular}{lccccc}
\hline Case & CD3 & CD4 & CD8 & CD56 & FOXP3 \\
\hline 1 & $92.4 \%$ & $77.3 \%$ & $64.6 \%$ & $0.1 \%$ & $6.1 \%$ \\
2 & - & - & - & - & - \\
3 & $82.7 \%$ & $71.2 \%$ & $29.8 \%$ & $0 \%$ & $0 \%$ \\
4 & $68.7 \%$ & $51.3 \%$ & $41.4 \%$ & $0 \%$ & $4.9 \%$ \\
5 & $81.2 \%$ & $73.8 \%$ & $47.7 \%$ & $0.1 \%$ & $11.4 \%$ \\
\hline
\end{tabular}

FOXP3: Forkhead box P3.

varied from $0 \%$ to $10 \%$. Because there was no preoperative evaluation, the transition of the T-cell population is unknown. However, it may change according to the degree 
of tumor necrosis. As the localization of T-cells may change because of surgical timing and chemotherapy effects, further study is necessary. There are reports that a decrease in $\mathrm{FOXP}^{+}$regulatory T-cells and increase in $\mathrm{CD} 8^{+} \mathrm{T}$-cells in peripheral blood contributes to prognosis prolongation of various cancer treatments (23-25). Furthermore, it is necessary to investigate the difference between resected tissue and peripheral blood regarding T-cell localization after treatment.

We were unable to draw a definitive conclusion on the usefulness of hepatectomy after adoptive chemoimmunotherapy because of the low number of patients included. Based on this report, we would like to accumulate further data. In recent years, the progress of chemotherapy for CRC has been remarkable. We can expect further prognosis prolongation with chemoimmunotherapy, and it may be useful as a conversion therapy for patients with unresectable CLMs.

\section{Conflicts of Interest}

The Authors declare that they have no conflict of interest in regard to this study.

\section{Acknowledgements}

The Authors thank the participating patients, their family members, and all researchers involved in this study.

\section{References}

1 Yoshida Y, Naito M, Yamada T, Aisu N, Daibo K, Mera T, Tanaka T, Naito K, Yasumoto K, Kamigaki T, Goto S, Yamashita $\mathrm{Y}$ and Hasegawa S: Adoptive chemoimmunotherapy using activated $\alpha \beta$ T-cells for stage IV colorectal cancer. Anticancer Res 36(7): 3741-3746, 2016.

2 Chi KH, Liu SJ, Li CP, Kuo HP, Wang YS, Chao Y and Hsieh SL: Combination of conformal radiotherapy and intratumoral injection of adoptive dendritic cell immunotherapy in refractory hepatoma. J Immunother 28(2): 129-135, 2005.

3 Lissoni P, Brivio F, Fumagalli L, Messina G, Meregalli S, Porro G, Rovelli F, Vigore L, Tisi E and D'Amico G: Effects of the conventional antitumor therapies surgery, chemotherapy, radiotherapy and immunotherapy on regulatory T-lymphocytes in cancer patients. Anticancer Res 29(5): 1847-1852, 2009.

4 Kamigaki T, Ibe H, Okada S, Matsuda E, Tanaka M, Oguma E, Kinoshita Y, Ogasawara S, Ono A, Makita K, Naitoh K and Goto S: Improvement of impaired immunological status of patients with various types of advanced cancers by autologous immune cell therapy. Anticancer Res 35(8): 4535-4543, 2015.

5 Topalian SL, Hodi FS, Brahmer JR, Gettinger SN, Smith DC, McDermott DF, Powderly JD, Carvajal RD, Sosman JA, Atkins MB, Leming PD, Spigel DR, Antonia SJ, Horn L, Drake CG, Pardoll DM, Chen L, Sharfman WH, Anders RA, Taube JM, McMiller TL, Xu H, Korman AJ, Jure-Kunkel M, Agrawal S, McDonald D, Kollia GD, Gupta A, Wigginton JM and Sznol M: Safety, activity, and immune correlates of anti-PD-1 antibody in cancer. N Engl J Med 366(26): 2443-2454, 2012.
6 Yoshida Y, Naito M, Yamada T, Aisu N, Kojima D, Mera T, Tanimura S, Tanaka T, Naitoh K and Yasumoto K. Clinical study on medical value of adoptive immunotherapy with chemotherapy for stage IV colorectal cancer (COMVI study). J Clin Oncol 34(suppl 4S): abstr 628, 2016

7 Tsoukas CD, Landgraf B, Bentin J, Valentine M, Lotz M, Vaughan $\mathrm{JH}$ and Carson DA: Activation of resting T lymphocytes by anti-CD3 (T3) antibodies in the absence of monocytes. The Journal of immunology 135(3): 1719-1723, 1985.

8 Takayama T, Sekine T, Makuuchi M, Yamasaki S, Kosuge T, Yamamoto J, Shimada K, Sakamoto M, Hirohashi S, Ohashi Y and Kakizoe T: Adoptive immunotherapy to lower postsurgical recurrence rates of hepatocellular carcinoma: a randomised trial. Lancet 356(9232): 802-807, 2000.

9 Sakamoto M, Nakajima J, Murakawa T, Fukami T, Yoshida Y, Murayama T, Takamoto S, Matsushita $\mathrm{H}$ and Kakimi K: Adoptive immunotherapy for advanced non-small cell lung cancer using zoledronate-expanded $\gamma \delta$ T-cells: a phase I clinical study. J Immunother 34(2): 202-211, 2011.

10 Yoshida Y, Hoshino S, Aisu N, Naito M, Miyake T, Tanimura $S$ and Yamashita Y: Pilot study of the early start of chemotherapy after resection of primary colorectal cancer with distant metastases (Pearl Star 01). World J Surg Oncol 11: 39, 2013.

11 Yoshida Y, Hirata K, Matsuoka H, Iwamoto S, Kotaka M, Fujita H, Aisu N, Hoshino S, Kosaka T, Maeda K, Kiyomi F and Yamashita Y: A single-arm phase II validation study of preventing oxaliplatin-induced hypersensitivity reactions by dexamethasone: the AVOID trial. Drug Des Devel Ther 9: 60676073, 2015.

12 Yoshida Y, Hoshino S, Aisu N, Naito M, Tanimura S, Mogi A, Tanaka T, Hirata K, Tamura K and Yamashita Y: Administration of chemotherapy via the median cubital vein without implantable central venous access ports: port-free chemotherapy for metastatic colorectal cancer patients. Int J Clin Oncol 20(2): 332-337, 2015.

13 Goto S, Noguchi A, Jinguji H and Takahara M: The therapeutic potential of immuno-cell therapy of cancer in combination with aminobisphosphonates. Anticancer Res 26(6a): 3989-3995, 2006.

14 Health UDo and Services H: National Cancer Institute. Common Terminology Criteria for Adverse Events (CTCAE) Version 4.0. US Department of Health and Human Services, National Institutes of Health, National Cancer Institute, 2009.

15 Eisenhauer EA, Therasse P, Bogaerts J, Schwartz LH, Sargent D, Ford R, Dancey J, Arbuck S, Gwyther S, Mooney M, Rubinstein L, Shankar L, Dodd L, Kaplan R, Lacombe D and Verweij J: New response evaluation criteria in solid tumours: revised RECIST guideline (version 1.1). Eur J Cancer 45(2): 228-247, 2009.

16 Clavien PA, Barkun J, de Oliveira ML, Vauthey JN, Dindo D, Schulick RD, de Santibanes E, Pekolj J, Slankamenac K, Bassi C, Graf R, Vonlanthen R, Padbury R, Cameron JL and Makuuchi M: The Clavien-Dindo classification of surgical complications: five-year experience. Ann Surg 250(2): 187-196, 2009.

17 Morioka T, Ohba K, Morita H, Takahashi G, Uchida H, Matsushita A, Sasaki S, Oki Y, Suda T, Kakudo K and Yoshino A: Non-islet cell tumor-induced hypoglycemia associated with macronodular pulmonary metastases from poorly differentiated thyroid carcinoma. Thyroid 24(2): 395-399, 2014. 
18 Shrimali RK, Yu Z, Theoret MR, Chinnasamy D, Restifo NP and Rosenberg SA: Antiangiogenic agents can increase lymphocyte infiltration into tumor and enhance the effectiveness of adoptive immunotherapy of cancer. Cancer Res 70(15): 6171-6180, 2010.

19 Correale P, Aquino A, Giuliani A, Pellegrini M, Micheli L, Cusi MG, Nencini C, Petrioli R, Prete S and De Vecchis L: Treatment of colon and breast carcinoma cells with 5-fluorouracil enhances expression of carcinoembryonic antigen and susceptibility to HLA-A (*) 02.01 restricted, CEA-peptide-specific cytotoxic Tcells in vitro. International journal of cancer 104(4): 437-445, 2003.

20 Tesniere A, Schlemmer F, Boige V, Kepp O, Martins I, Ghiringhelli F, Aymeric L, Michaud M, Apetoh L and Barault L: Immunogenic death of colon cancer cells treated with oxaliplatin. Oncogene 29(4): 482-491, 2010.

21 Lake RA and Robinson BW: Immunotherapy and chemotherapy a practical partnership. Nat Rev Cancer 5(5): 397-405, 2005.

22 Bismuth H, Adam R, Levi F, Farabos C, Waechter F, Castaing D, Majno $\mathrm{P}$ and Engerran L: Resection of nonresectable liver metastases from colorectal cancer after neoadjuvant chemotherapy. Ann Surg 224(4): 509-520; discussion 520-502, 1996.
23 Wolf D, Wolf AM, Rumpold H, Fiegl H, Zeimet AG, MullerHolzner E, Deibl M, Gastl G, Gunsilius E and Marth C: The expression of the regulatory $\mathrm{T}$ cell-specific forkhead box transcription factor FOXP3 is associated with poor prognosis in ovarian cancer. Clin Cancer Res 11(23): 8326-8331, 2005.

24 Salama P, Phillips M, Grieu F, Morris M, Zeps N, Joseph D, Platell C and Iacopetta B: Tumor-infiltrating FOXP3 ${ }^{+} \mathrm{T}-$ regulatory cells show strong prognostic significance in colorectal cancer. J Clin Oncol 27(2): 186-192, 2009.

25 Sato E, Olson SH, Ahn J, Bundy B, Nishikawa H, Qian F, Jungbluth AA, Frosina D, Gnjatic S, Ambrosone C, Kepner J, Odunsi T, Ritter G, Lele S, Chen YT, Ohtani H, Old LJ and Odunsi K: Intraepithelial CD8+ tumor-infiltrating lymphocytes and a high $\mathrm{CD}^{+} /$regulatory $\mathrm{T}$-cell ratio are associated with favorable prognosis in ovarian cancer. Proc Natl Acad Sci USA 102(51): 18538-18543, 2005

Received May 2, 2017

Revised May 18, 2017

Accepted May 19, 2017 